\title{
Paulo Freire e o papel das Agências de Cooperação Europeias no apoio à Educação Popular no Brasil
}

\author{
Sérgio Haddad * \\ http://dx.doi.org/10.1590/0103-7307201407507
}

\section{Resumo}

0 artigo foi redigido como parte de um estudo mais amplo, que tem por objetivo investigar o contexto e as intenções em que práticas de educação popular foram produzidas na década de 1970 e 80 no Brasil, identificando os fatores que permitiram seu * Ação Educativa Assessoria Pesquisa e Informação, São Paulo, SP-Brasil. sergiohaddad@terra.com.br desenvolvimento. 0 objetivo específico deste texto concentra-se em discutir o papel que as agências de cooperação europeias tiveram no apoio às entidades da sociedade civil brasileira, em sua atuação no campo da educação popular naquele período, e a influência do pensamento de Paulo Freire. Para tanto, além de bibliografia sobre o tema, foram utilizadas entrevistas com os principais oficiais de projetos daquelas agências que atuaram apoiando trabalhos no Brasil.

\section{Palavras-chave:}

Paulo Freire, educação popular, cooperação internacional, organizações não governamentais, Comunidades Eclesiais de Base. 


\title{
Paulo Freire and the role of the European Financing Agencies in the support of Popular Education in Brazil
}

\begin{abstract}
This article was drawn up as part of a broader study that has the objective of investigating the context and the intentions in which popular education practices were carried out in Brazil in the 1970's and 1980's, identifying factors that permitted their development. The specific objective of this text focuses on discussing the role that the European cooperation agencies had in their support of Brazilian civil society organizations in their action in the field of popular education during that period as well as with regard to the influence of Paulo Frere's thought. Towards this, besides offering a bibliography on the theme, interviews with the principal officials related to projects that supported work in Brazil were also analyzed.
\end{abstract}

Keywords

Paulo Freire, popular education, international cooperation, non-governmental organizations, basic ecclesial communities. 


\section{Introdução}

Durante os anos 1970, período de plena ditadura no Brasil, no contexto da repressão política que se instalou contra institucionalidades, grupos, organizações e indivíduos, novas formas do agir político se desenvolveram como mecanismo de reconstrução democrática e de defesa dos direitos humanos que eram violados constantemente. Entre essas formas, duas merecem destaque: as Comunidades Eclesiais de Base - CEBs - e as Organizações Não Governamentais (ONGs). As primeiras são fruto do movimento da Igreja Católica de aproximação com setores populares de forma crítica, amparada pelas orientações do Concílio Vaticano II e da Teologia da Libertação; as segundas se constituíram como alternativa política para pessoas e grupos que vinham de partidos políticos e de universidades e instituições públicas e privadas atingidas pela perseguição dos órgãos de repressão.

Essas novas formas do agir político tinham em comum metodologias de trabalho com os setores populares, orientadas para aumentar a tomada de consciência sobre os problemas vividos pela população e ampliar a sua organização, para a defesa dos seus interesses e contra o regime repressivo. Quase sempre a referência pedagógica dessas metodologias de trabalho tinha Paulo Freire como centralidade, apesar de o educador estar exilado na Suíça. Seus escritos circulavam de forma reservada nos primeiros anos.

As CEBs foram muito estudadas naquele período e, posteriormente, nos tempos de redemocratização. Já, o mundo das ONGs, nem tanto: sua semiclandestinidade e seu pequeno número acabaram por torná-las quase invisíveis à sociedade em geral, tendo ganhado presença pública apenas por ocasião do encontro das Nações Unidas no Rio de Janeiro, conhecido como Rio 92, quando milhares de organizações brasileiras e internacionais estiveram presentes em um evento paralelo na praia do Flamengo. Se as CEBs tinham por trás a Igreja Católica como apoio político e financeiro, as ONGs viviam da cooperação internacional, principalmente a europeia.

Paulo Freire, vivendo em Genebra, não só acabou por influenciar, com suas ideias, a cooperação internacional, tornando-a menos assistencialista e mais crítica no apoio às organizações que trabalhavam processos de transformação social nos países do Sul, entre as quais as ONGs, como também visitou várias das agências do Norte, para falar sobre a realidade repressiva desses países e sobre o seu pensamento pedagógico.

Este texto tem como pano de fundo essa realidade. Trata-se de buscar informações sobre uma realidade muito pouco conhecida. Para tanto, a metodologia utilizada foi a 
da revisão bibliográfica sobre a temática, combinada com visitas às agências de cooperação e entrevistas com pessoas que eram responsáveis pelo apoio às entidades e a seus projetos educacionais no Brasil. 0 conteúdo a seguir é um dos produtos de uma pesquisa mais ampla.

\section{A cooperação europeia}

A cooperação internacional ou cooperação para o desenvolvimento dos países europeus estudados neste artigo (França, Alemanha, Bélgica e Holanda), de uma maneira geral, esteve inserida no conjunto de ações que os governos estruturaram como política estatal para países em desenvolvimento ou em situação de emergência no âmbito da sua política externa. Evidentemente, cada um definiu sua política a partir não apenas de demandas e dinâmicas internas à sua história, às suas formas de organização política e social, ao seu lastro cultural, mas também de sua inserção na cena mundial e da relação com os países apoiados por sua política externa de cooperação. É possível afirmar, no entanto, com alguma margem de segurança, que há um elemento comum: a participação de entidades da sociedade civil de cada país, seja na estruturação das políticas (ou em parte de seus programas), seja na sua execução. Uma hipótese que explicaria esse traço comum parece ter a ver com a própria constituição de um de seus atores mais proeminentes, as ONGs e o campo que elas aglutinam¹.

Philipe Ryfman (2009), no livro Les ONG, reconstitui a história das entidades do Norte que têm realizado cooperação internacional de seus primórdios até a atualidade. Nele, ressalta alguns pontos importantes que permitiram a constituição do campo da solidariedade internacional. o primeiro seria o processo de laicização ou secularização das atividades caritativas ligadas exclusivamente às Igrejas desde o século XVII na Europa e depois, pouco mais à frente, nas colônias norte-americanas. Outro aspecto levantado pelo autor é o surgimento, no século XIX, do direito internacional, que cons-

1. É importante destacar que, ainda que as organizações não governamentais tenham sua origem em processos históricos que remontam a vários séculos, a denominação ONG é recente, uma criação da segunda metade do século $X X$, a partir da ampliação da participação de organizações da sociedade civil em processos políticos institucionais das Nações Unidas. Em realidade, a autodenominação das organizações brasileiras como ONGs se deu apenas a partir de meados da década de 1980 . truiu um corpo jurídico de normas que regulavam as relações internacionais nos momentos de paz e de conflitos. Por fim, a constituição da noção de direitos humanos, ancorada no lluminismo. É por essa noção de direitos humanos que se orienta parte significativa da ação das entidades de cooperação e de defesa de populações em situações de emergência. 
Se essas referências são longínquas do ponto de vista temporal, elas montam o pano de fundo de orientação e sustentação institucional e jurídica que permitirá a constituição de programas e ações bilaterais e multilaterais das políticas de cooperação internacional; por outro lado, constituem lastro para percepção social da necessidade e da justeza da solidariedade internacional como uma ação individual, coletiva e institucional, reconhecendo o papel da sociedade civil nessa atividade.

As primeiras entidades humanitárias datam do século XIX e surgiram por ocasião das guerras dentro da própria Europa e, de acordo com Roque (2001), são baseadas em fins morais ou religiosos. Como exemplo, ele destaca o surgimento em 1839, na Inglaterra, da British and Foreign Anti-Slavery Society, bem como, em 1860, das Sociétés de Secours Aux Blassés, que iriam, mais à frente, formar as sociedades nacionais da Cruz Vermelha. Essa última seria a inspiração para a organização, pela Igreja Católica, da Rede Cáritas no começo do século XX.

Os fatores explicativos da expansão desse campo são, grosso modo, as duas guerras mundiais e o processo de descolonização da África. O surgimento das grandes entidades de atendimento emergencial a civis afetados pelas guerras foi uma novidade no cenário europeu. Foi nesse contexto que nasceram importantes entidades internacionais que mais tarde, a partir dos anos 1970, teriam importante participação na cooperação com o Brasil: a Save the Children, em Londres, em 1919; a Plan International em 1937; a britânica Oxfam em 1942; a Care, nos Estados Unidos, em 1945; e a World Vision em 1950.

Roque (2001) considera que o Plano Marshall para o processo de reconstituição da Europa, no pós-Segunda Guerra, ofereceu um modelo que influenciaria as políticas de cooperação internacional de vários países europeus. Pedrotti (2005), no seu estudo sobre a cooperação alemã, corrobora a influência do Plano, ao afirmar que foi a fonte de inspiração para a estruturação da cooperação técnica alemã. Roque acrescenta ainda que o surgimento das Nações Unidas e das Instituições de Breton Woods é elemento que fornece não apenas uma determinada lógica de atuação política que supera os limites dos Estados Nação, como também a legitimidade para os processos de cooperação internacional para além das ações caritativas, em geral desenvolvidas pelas Igrejas cristãs. Em suas palavras,

a cooperação internacional se converteu em um aspecto crucial das relações norte-sul, instrumento essencial de certo paradigma de desenvolvi- 
mento sob a liderança dos Estados Unidos. Os fundos movimentados pela cooperação internacional também serviram à estratégia de contraposição a uma possível expansão comunista, refletindo diretamente as tensões da Guerra-Fria (Roque, 2001, p. 23).

Outro processo político importante e que também se relaciona com as tensões da Guerra Fria foram as lutas por independência em países africanos e asiáticos, ocorridas principalmente a partir da década de 1960. A situação vivida nesses países levou à criação de várias agências de cooperação internacional. A Netherlands Organisation for International Assistance - Novib - surgiu em 1956, em função da experiência de holandeses que viveram na Indonésia. Em 1958, foi criada na Alemanha, por iniciativa da Igreja Católica, a Misereor, da Campanha Contra a Fome e Enfermidades do Mundo. No ano seguinte, a Igreja Protestante Alemã organizou a campanha Pão para o Mundo, que deu origem a uma agência de cooperação com esse nome. Em 1961 surgiu na Bélgica a Brooderlijk Delan/Entraide et Fraternité, organização belgo-francesa que se originou de uma campanha contra a fome no Congo. Também em 1961 se estruturou o Comité Catolique Contre la Faime, organização francesa ligada à Igreja Católica e conhecida como CCFD. A letra D da sigla, que significa desenvolvimento, foi agregada em 1966. Apenas uma das organizações que compõem o contexto da pesquisa foi fundada em um momento anterior e vinculada às questões da Segunda Guerra Mundial: Comité Inter-Mouvements Auprès des Evacués - Cimade -, criada por protestantes franceses após a invasão da Polônia em setembro de $1939^{2}$.

Até meados da década de 1960 quase a totalidade dos recursos da cooperação internacional desse tipo advinha de fontes privadas. Importa ressaltar que tal solidariedade nasceu no contexto da dura experiência vivenciada durante o período da guerra, unida ao enriquecimento dessas sociedades a partir dos processos de reconstrução nos anos seguintes. Por outro lado, tanto os processos de descolonização na África e na Ásia quanto o crescimento econômico de algumas sociedades europeias

2. Sobre a cooperação belga, ver, em especial: DEVELTERE, Patrick; MICHEL, Aristide. Chronique d'un demi-siècle de cooperation belge au developpement. Bruxelas: SPF Affaires étrangères, Commerce extérieur et Cooperation au Développement, 2009. Disponível em: http://diplomatie. belgium.be/fr/binaries/chronique_demi-siecle_cooperation_belge_tcm313-98710.pdf. Acesso em: 10 out. 2013. também podem ser considerados fatores que explicam a constituição de políticas estatais para a cooperação internacional.

O crescimento econômico experimentado pelas sociedades europeias a partir da metade dos anos 1950 levou muitas empresas a expandirem 
seus negócios em busca de novos mercados. Para os países europeus que tiveram colônias, os processos políticos da década de 1960 produziram ações comerciais de novos tipos com os países do Sul, como foram os casos da França, da Holanda e da Bélgica. Contudo, a América Latina também passou a ser estratégica do ponto de vista econômico e político. Como consequência, as empresas pressionaram os governos para a estruturação de uma política de cooperação internacional que apoiasse essas ações comerciais. Em um momento posterior, as organizações da sociedade civil, em especial aquelas vinculadas às Igrejas cristãs, também passaram a fazer pressão para acessar os recursos públicos, com destaque para os casos holandês e alemão. Buscavam recursos para a expansão do trabalho pastoral e social, acompanhando as comunidades estrangeiras que haviam se deslocado para os países latino-americanos, como no caso do Sul do Brasil.

A situação da Alemanha tinha alguns contornos bastante específicos. Segundo Pedrotti (2005), no período inicial do pós-Segunda Guerra, a Alemanha tinha sua autonomia controlada, graças à constituição do Ministério da Cooperação (1961), estratégia importante para a conciliação dos interesses alemães, no que se refere tanto à expansão dos mercados quanto à melhoria da imagem internacional do país, que tornou possível o acesso aos recursos públicos pelas organizações da sociedade civil. Como decorrência, foi criada pelas Igrejas protestantes a Associação Protestante para a Cooperação ao Desenvolvimento - EZE -, ${ }^{3}$ em 1962. Já a Igreja Católica utilizou-se da estrutura da Misereor para receber esses recursos.

O modelo criado pelo Estado alemão parece ter inspirado a estrutura de cooperação internacional do Estado holandês no começo dos anos 1960. E, do mesmo modo que a EZE foi criada em 1964, nasceu a Interchurch Organization for Development Cooperation - Icco - como uma organização intermediária de cofinanciamento de projetos e órgãos diaconais missionários das Igrejas protestantes holandesas e da católica Central de Organizações de Cofinanciamento para o Desenvolvimento - Cebemo ${ }^{4}$. Contudo, uma diferença importante no modelo holandês incluía também uma organização laica, a Novib, com o objetivo de criar uma distribuição adequada dos recursos, em termos de filiação ou não às Igrejas.

No caso francês, a presença das organizações vinculadas à Igreja Católica foi muito forte, havendo, portanto, características próprias na construção do campo da cooperação e da solidariedade

3. Depois Church Development Service - EED, e, finalmente, uniu-se à Pão para o Mundo, em 2013 4. Hoje Cordaid - Catholic Organisation for Relief and Development Aid. 
internacional. Ainda nos anos 1950, dois importantes organismos da sociedade civil francesa foram criados: em 1955, o Institut de Recherche et d'Action sur la Misère du Monde, que deu origem ao Institut de Recherche et d'Application des Méthodes de Développement (Iram); e, em 1958, Padre Lebret criou o Instituto Internacional de Pesquisa e de Formação, Educação para o Desenvolvimento (Irfed). Esse Instituto foi decisivo na constituição de outros organismos de cooperação, além de ser um importante centro de estudos e debates sobre as questões do Terceiro Mundo e do desenvolvimento. 5

Como podemos perceber, a cooperação internacional europeia nasceu de um conjunto de interesses econômicos, políticos e religiosos, que levaram a um incremento da sua participação com a América Latina, nos anos 1960 e seguintes, em um contexto de ditaduras políticas. Entre esses interesses, a solidariedade internacional apoiou um conjunto de organizações não governamentais no seu trabalho político-pedagógico de reconstruir a democracia naqueles países.

5. Sobre a cooperação francesa, ver: HATTON, Jean-Marie. Note sur la stucturation progressive des organisations de solidarité internationales (OSI) dans leur relation avec les pouvoirs publics: Quelques repères historiques. Disponível em: http://www.coordinationsud. org/wp-content/uploads/structuration_milieuOSIFrance. pdf. Acesso em: 10 out. 2013.

TROUBÉ, Christian. L'humanitaire en turbulences, les ONG face aux défis de la solidarité internacionale. Paris: Éditions Autremente, 2006.

COORDINATION SUD. Présentation du secteur des ONG françaises. Disponivel em: http://www.coordinationsud. org/Le-secteur-des-ONG-francaises. Acesso em: 10 out. 2013.

6. As primeiras entrevistas foram realizadas entre os dias 10 e 15 de setembro de 2010 na França e na Bélgica. Foram entrevistadas as seguintes pessoas: John Slander - agência Oxfam Novib; Jackie Fabre e Henryène de Chaponay agência CCFD; Jean-Marie Fardeau - agência CCFC; André Benoit - agência Broederlijk Delen; Iolanda Bittencourt agência Entraide et Fraternité.

A segunda viagem internacional (Alemanha e Holanda) foi realizada de 7 a 17 de outubro de 2010. Nela foram entrevistadas as seguintes pessoas: Jürgen Stahn - Agência Pão para o Mundo; Pim Verhallen - agência Icco; Anneke Jansen - agência Oxfam Novib; Luciano Wolff e Wolfgang Kaiser - agência EED; Úrsula Sen Gupta - agência EED; Manfred Wadehn - agência EED; Alfred Ruppert - agência Misereor.

\section{A Cooperação Internacional por seus agentes}

Para identificar as razões que orientaram a política de cooperação internacional europeia no Brasil nos seus primórdios e o papel que a educação popular e Paulo Freire tiveram naquele contexto, foram realizadas entrevistas com oficiais de projetos de ONGs europeias. A maioria das pessoas entrevistadas que atuaram nas agências holandesas e alemãs de cooperação internacional ${ }^{6}$ iniciou os seus trabalhos a partir da segunda metade da década de 1970. Apenas uma das entrevistadas esteve nessas organizações em um período anterior, nos anos 1960. Grande parte também ficou por mais de 20 anos nesse trabalho. Muitos foram os primeiros responsáveis pela estruturação das ações de cooperação com a América Latina e o Brasil.

Um elemento recorrente nos depoimentos foi a menção ao ambiente político das agências naque- 
le período, destacando a presença de pessoas com uma visão inovadora e politizada na direção dessas agências. É o que nos conta Jurgen Stahn, ao afirmar que, ao ingressar na alemã Pão para o Mundo como secretário para a América Latina, em 1978, encontrou um ambiente de muita abertura e um diretor que conhecia a realidade latino-americana. 0 mesmo foi dito por Alfred Rupert: mencionou que, quando assumiu o cargo de responsável pelo Brasil, na também alemã Misereor, em 1976, a pessoa responsável pela América Latina foi substituída por outro funcionário, caracterizado por ele como “um revolucionário”. Úrsula Sem Gupta, da agência EED, refletindo sobre o contexto político do final dos anos 1960 e começo dos anos 1970, afirma que, naquele mesmo período, assumiu a chefia da EZE um novo diretor, que possuía uma visão mais política, dado que o clima da sociedade alemã era mais aberto para as questões da América Latina. Para Úrsula, o maior interesse da sociedade alemã por esse continente se explica por ele ser mais "europeu” do que a África e a Ásia. Para Anneke Jansen, da agência Oxfam Novib, o diretor geral da holandesa Novib, à época, tinha uma visão muito política sobre o papel que a agência poderia cumprir nas lutas contra a ditadura que ocorria no Brasil, havendo, inclusive, "fundos secretos" que eram utilizados para ações de caráter mais político. Havia também uma militância política dos funcionários da Novib, que influenciava nos processos de cooperação. Tanto Anneke quanto John Schlanger, da mesma agência, mencionaram o fato de que uma das primeiras organizações brasileiras financiadas pela Novib havia sido o Centro Brasileiro de Análise e Planejamento - Cebrap (SP) -, em razão da explosão de uma bomba, na sede da organização brasileira, pelos órgãos de repressão.

No que se refere às dinâmicas sociopolíticas que possibilitaram as mudanças no perfil das relações de cooperação nos anos 1970, são vários os aspectos apontados pelos entrevistados. Segundo Jurgen Stahn, a América Latina não era prioridade para a evangélica Pão para o Mundo, por ser o continente considerado "católico". O foco era a África, continente com uma forte influência missionária das Igrejas evangélicas alemãs no século XIX. Quando Stahn começou a trabalhar em Pão para o Mundo, a lógica eclesiástica dominava os apoios, havendo a expectativa de que trabalhassem junto com as estruturas das Igrejas protestantes. Para Jurgen, no pós-1968, as Igrejas protestantes começaram a ampliar suas perspectivas, à medida que perceberam que a lógica deveria ser "pão para o mundo e não pão para a Igreja" e que os principais agentes do desenvolvimento e do progresso social, cultural e dos direitos humanos nem sempre eram as Igrejas. 
Úrsula informa que, até o começo dos anos 1970, os projetos chegavam à EZE principalmente por intermédio das Igrejas e, em geral, se relacionavam à construção e à melhoria de escolas e hospitais. Contudo, a partir desse momento, as agências passaram a debater conceitos como o de desenvolvimento na orientação dos seus apoios. Destaca ainda que o Conselho da EZE tinha algumas resistências ao trabalho com ONGs e movimentos sociais, mas, no caso brasileiro, essa dimensão era "disfarçada" pelo argumento de que tais organizações tinham uma base cristã, o que não era possível no caso da Índia, por exemplo. Manfred Wadehn, da agência EED, reforça a análise de Úrsula: afirma que havia diferenças no sentido de maior ou menor politização das organizações, e essas diferenças apareciam nos trabalhos apoiados na América Latina.

O contexto político das sociedades latino-americanas nos anos 1970, a maior parte delas vivendo ditaduras militares bastante repressivas, é apontado por todas as pessoas entrevistadas como tendo sido um elemento fundamental. As sociedades holandesa e alemã, naquele período, estavam mais abertas politicamente, o que contrastava fortemente com o vivido pelas sociedades latino-americanas. Pode-se afirmar que a dimensão de solidariedade das ações de cooperação foi o traço mais marcante nas relações estabelecidas, incluindo os asilos políticos concedidos a um imenso contingente de militantes sul-americanos.

Jurgen Stahn, da Agência Pão para o Mundo, destaca que as comunidades de exilados chilenos, argentinos e bolivianos, vítimas das ditaduras militares dos seus países, eram bastante atuantes na Alemanha, inclusive com palestras na Pão para o Mundo. Esse processo gerou a doação de um montante razoável de recursos financeiros para o apoio das ações das agências no continente latino-americano. Pim Verhallen, da agência Icco, considera que o golpe de estado no Chile, com suas fortes imagens, foi determinante para a abertura da sociedade holandesa para a América Latina nos anos 1970.

No caso da Novib, única organização laica, Anneke Jansen aponta que o programa dessa agência para o Brasil foi montado a partir das demandas de organizações da sociedade civil, que precisavam de apoio nos campos da educação popular e também de pesquisa, dado que as universidades brasileiras não tinham, naquele momento, espaço para a produção de pensamento crítico.

A denominada "abertura das Igrejas" é outra marca muito forte desse período, do ponto de vista tanto do pensamento teológico quanto das ações concretas, criando as condições de legitimidade sócio-política nos dois lados da relação, ou seja, para 
as organizações que doavam os recursos na Europa e para aquelas que os recebiam na América Latina.

Tomando como referência a influência do Concílio Vaticano II, Pim afirma que a sociedade holandesa católica se engajou nos processos e nos debates, mas por um período muito curto. Na sequência, a dimensão latino-americana do Concílio, em sua opção preferencial pelos pobres, foi bastante aceita, e a renovação eclesial na Igreja e na doutrina social teve um impacto muito forte nas sociedades latino-americanas.

No contexto da Teologia da Libertação, o tema da participação dos pobres como fator de mudança social passou a ser central. Para Jurgen Stahn, nos anos 1970 e 1980, seu papel foi importante tanto no seio das Igrejas quanto na sociedade. Em sua opinião, os temas e as questões trazidos por essa concepção teológica foram um grande desafio para a Igreja oficial na Alemanha. Esse elemento de desafio também é ressaltado por Jan van Bentum, oficial de projetos da holandesa Icco. Segundo ele, o fundamental nas ações de cooperação internacional naquele momento era a criação de condições para que as pessoas excluídas pudessem ter mais espaço para participar dos processos de tomada de decisão naquilo que dizia respeito às suas vidas. $\mathrm{E}$ era nesse sentido que ele compreendia o apoio ao trabalho das pastorais da Igreja Católica. Sua proposta de realizar ações de cooperação com as pastorais católicas foi uma grande novidade para a Icco, por serem ações completamente distintas daquelas que as Igrejas protestantes tradicionalmente realizavam.

A mesma importância conferida ao fortalecimento das organizações populares é ressaltada por Alfred Rupert, quando afirma que, em que pese o fato de que todos os projetos da Misereor fossem articulados a partir da Igreja Católica e seus representantes, ele considerava fundamental apoiar a "luta do povo". Assim sendo, a formação política e comunitária por meio da educação popular, que tinha como referência central o pensamento de Paulo Freire, era elemento essencial nas escolhas dos projetos que deveriam ser apoiados.

0 “idioma comum" criado pelas ações das Igrejas ancorou-se fortemente na noção de direitos humanos. Úrsula considera a criação da Coordenadoria Ecumênica de Serviços - Cese ${ }^{-7}$ no Brasil um marco na mudança das concepções das agências e destaca o conceito de direitos humanos trazido por essa organização como um elemento fundamental. Para Pim Verhallen, as relações estabelecidas mais fortemente entre a sociedade holandesa e as sociedades latino-americanas, quando comparadas à África e 
à Ásia, explicam-se pelo fato de que ambas falavam o mesmo idioma ocidental dos direitos humanos.

A presença das ações das Igrejas também pode ser observada pela preponderância de organizações brasileiras a elas vinculadas, citadas $^{8}$ como sendo os primeiros apoios mais importantes dados pelas agências alemãs e holandesas naquele período. Metade das organizações citadas tinha vínculo direto com as Igrejas ou com o ecumenismo. São os casos da Comissão Pastoral da Terra, do Conselho Indigenista Missionário, da Pastoral Operária, da Diakonia, da Igreja Evangelista da Congregação Luterana, da Comissão de Justiça e Paz de São Paulo, da Coordenadoria Ecumênica de Serviço - Cese -, do Centro Ecumênico de Documentação e Informação - Cedi -, por exemplo. Outras organizações, como a Federação de Órgãos para Assistência Social e Educacional - Fase - e o Centro de Estudos e Ação Social e a Articulação Nacional de Movimentos Populares e Sindicais - Ceas - têm, em suas origens, a influência direta da Igreja Católica. Assim sendo, as redes de contato das organizações vinculadas às Igrejas com as agências de cooperação internacional e os grupos que organizavam as lutas e as resistências à ditadura possibilitaram a conformação das políticas e dos programas de cooperação para a América Latina e o Brasil.

Alfred Rupert analisa que contatos com os bispos progressistas brasileiros possibilitaram à Misereor ter o aval para o apoio da Igreja alemã, mais conservadora. Contudo, em que pese o apoio das sociedades holandesa e alemã e a forte presença das Igrejas cristãs, havia momentos de tensão com o governo militar brasileiro que, por vezes, pressionava os governos dos países europeus; e situações de tensão política, provocadas pelos aparatos de segurança brasileiros. Outros depoimentos informam sobre as pressões sofridas pelos agentes, no trabalho de apoio às ONGs e aos movimentos sociais no Brasil.

André Benoit entrou na belga Broederlijk Delen em 1982. Em 1986 foi trabalhar como encarregado dos projetos para a América Latina. Para ele, houve três momentos em Broederlijk Delen, com relação à concepção de suas ações de cooperação: em um primeiro momento, o sentido era caritativo, a ajuda aos pobres; em um momento seguinte, passou-se a reconhecer as injustiças presentes nas estruturas sociais dos países do Sul; por fim, houve o reconhecimento

8. É importante destacar que as organizações citadas foram aquelas que os(as) entrevistados(as) lembravam no momento, não significando a totalidade das organizações apoiadas nos anos 1970-1980. da produção, pelos países do Norte, dessas injustiças. Os conceitos que orientavam suas escolhas eram o trabalho com grupos excluídos e os proje- 
tos que pudessem influir nas estruturas produtoras de injustiças - por isso, a ênfase em Direitos Humanos -, com atividades que melhorassem as condições de vida e com a educação popular conjugada à formação técnica.

Foi por seu trabalho na Action Catholique d' Enfance que Jackie Fabre se aproximou do Comitê Católico contra a Fome e pelo Desenvolvimento - CCFD -, fazendo parte de um conselho externo composto por membros dos movimentos vinculados à Ação Católica Francesa. Segundo a avaliação de Fabre, o CCFD desenvolveu um trabalho diferente de cooperação e solidariedade internacional, por influência dos movimentos da Ação Católica, mas, principalmente, pelo fato de que, a partir da metade dos anos 1960, teve que lidar com as ditaduras da América Latina, por força da presença dos refugiados latino-americanos, o que transformou muitas coisas no CCFD. Fabre destaca ainda, e de modo muito especial, a atuação de D. Helder Câmara, que questionou muitas coisas no modelo de cooperação.

Os contatos de Iolanda Bittencourt com a Ação Católica levaram-na a participar de Entraide et Fraternité em meados dos anos 1960. No início da década de 1970, ela se tornou responsável pelos projetos vindos da América Latina. Foram definidos critérios de seleção e, aos poucos, diminuiu-se a perspectiva assistencialista, para trabalhar com a lógica de ações em parceria. A maioria era de organizações da base da Igreja Católica, mas sem a intermediação das estruturas eclesiais. Segundo Iolanda, o episcopado belga lhe dava muita liberdade e confiança. Citou como exemplo o que se passou em meados da década de 1970: naquele momento, havia na África várias lutas pela independência, e um dos "troncos" - assim se nomeava a estrutura das coletas de doações - teria como destino o apoio aos movimentos armados de libertação. Com relação à América Latina, Iolanda afirma que não havia apoios semelhantes. Mas ela realizava ações de apoio aos exilados que chegavam à Bélgica.

No Brasil, Iolanda recorda que sua entidade apoiou o trabalho das Comunidades Eclesiais de Base - CEBs -, e ela, inclusive, participou do primeiro encontro nacional dessas comunidades, ocorrido em Vitória em 1973. Além das CEBs Entraide et Fraternité, também apoiou o Centro de Ação Comunitária - Cedac - (RJ), a Nova - Pesquisa e Assessoria em Educação (RJ), o Centro de Trabalho e Cultura - CTC - (PE), a Fundação do Desenvolvimento Integrado do São Francisco - Fundifran - (BA), o Centro Ecumênico de Documentação e Informação - Cedi - (RJ/SP) e o Centro de Direitos Humanos de São Paulo. Iolanda menciona ainda relações com Dom Tomás Balduíno, Dom Luiz Fernandes e Dom Helder Câmara, ressaltando que, com este último, as relações nun- 
ca foram de apoio financeiro, mas de intercâmbios políticos. Ela destaca a importância da presença de Dom Helder em Bruxelas, pois suas palestras na Universidade de Louvain - nas quais ele enfatizava a importância de atuar para a mudança a partir da própria Europa - atraíam muitas pessoas, especialmente jovens.

Para Jean Marie Fardeau, da agência CCFC, cada ONG francesa tinha "sua" ONG brasileira, dada a força das relações pessoais estabelecidas nos anos 1970, bem como em função do conhecimento específico da realidade brasileira. Cita pessoas de organizações com que estabeleceram parcerias: Jean Pierre Leroy, da Fase; Betinho, do Instituto Brasileiro de Análises Sociais e Econômicas - Ibase -, dado que a organização se tornou referência sobre o Brasil; Dom Tomás Balduíno, em função das ações e da importância da Comissão Pastoral de Terra - CPT -; Dom Hélder Câmara. Analisando as dinâmicas da cooperação francesa, Jean Marie afirma que o debate na França foi marcado pelas chamadas posições terceiro-mundistas, cujo foco argumentativo se concentrava nas questões relacionadas ao papel e à responsabilização dos países do Norte pelas situações vividas nos países do Sul.

\section{A Cooperação Internacional, Paulo Freire e a Educação Popular}

O conjunto das pessoas entrevistadas reconhece a centralidade da educação popular e do pensamento freireano nos projetos apoiados pelas agências durante aquele período, ainda que não tivesse sido esse um critério para sua seleção e aprovação.

Para dois dos entrevistados, a educação popular e o método de alfabetização de adultos de Paulo Freire foram também experiências por eles desenvolvidas antes mesmo do seu trabalho nas agências com as organizações brasileiras. São os casos de Jan van Bentum e sua esposa Janneke e também de Anneke Jansen.

No primeiro caso, a experiência com educação popular remonta aos momentos iniciais do trabalho de ambos como educadores ainda na Holanda, pois, segundo Janneke, o método Paulo Freire "tinha as palavras", o que queria dizer que Paulo Freire deu um sentido teórico a um conjunto de práticas que se realizavam de modo não conectado.

Quando veio trabalhar no Brasil em projetos vinculados à Igreja evangélica reformada da Holanda, o casal desenvolveu, em Santo André, trabalhos de educação popular com crianças, em sua maioria nordestina e com mais de 6 anos, que frequentavam a escola formal, mas não sabiam ler. Jan trabalhava com jovens da comunidade que atuavam com as crianças no desenvolvimento da linguagem, por meio de 
brincadeiras e contação de histórias, pois, em sua concepção, a educação é muito mais do que apenas a habilidade da leitura: é, essencialmente, a criação de processos de conscientização sobre o mundo. 0 trabalho que realizaram posteriormente em Campo Limpo (zona sul da cidade de São Paulo) foi basicamente voltado à educação popular para adultos.

No caso de Anneke Jansen, durante um período em que esteve na Guiné Bissau, antes de tornar-se responsável pelos projetos no Brasil, interessou-se pela educação popular e considerou, quando do seu retorno à Holanda, que este seria um campo de trabalho possível. Naquele momento havia nas escolas holandesas um contingente de mulheres adultas que queriam concluir seus estudos interrompidos no passado. Em função disso, foi fácil para Anneke conseguir um emprego na área da chamada "segunda chance de educação para adultos" (especialmente mulheres), usando a infraestrutura das escolas públicas que estavam ociosas. Havia alguma proximidade entre a educação popular e a segunda chance de educação para adultos, pois esta consistia nos processos de leitura, operações matemáticas fundamentais e reflexão sobre o que estava acontecendo na realidade. Ao lado dos grupos de mulheres, estavam imigrantes turcos e marroquinos que chegavam, em grande número, à Holanda e também jovens com mais de 16 anos, que haviam abandonado os estudos e queriam retomá-los. Durante o período em que deu aulas de holandês, Anneke tentou aplicar alguns princípios do método Paulo Freire; contudo, encontrou algumas dificuldades, em particular com os imigrantes marroquinos e turcos, dadas as limitações culturais deles para falar sobre suas experiências para uma mulher.

Outros entrevistados, como Jurgen Stann e Pim Verhallen, tiveram seus primeiros contatos com a educação popular e/ou o método de alfabetização de adultos de Paulo Freire por meio de experiências em outros países da América Latina. No caso de Jurgen, quando estava na Universidade de Colômbia. Já Pim citou as experiências peruanas formadas a partir da metodologia do Sistema Nacional de Mobilização Nacional - Sinamos -, de Velasco Alvarado', como um exemplo importante, na medida em que essa metodologia fomentou a criação de um grande número de ONGs de primeira geração. Para ele, este é um dos elementos que explica o fato de que, durante anos, o Peru foi o país que mais recebeu recursos de Cebemo e de outras agências europeias.

Pim Verhallen afirma ainda - posição, em certo sentido, compartilhada por Jurgen Stahn - que os processos de educação popular constituíram a realização prática e a orientação

9. Juan Velasco Alvarado, presidente do Peru de 1968 a 1975. 
metodológica de muitos dos conteúdos do Concílio Vaticano II. Para ele, as organizações brasileiras no final dos anos 1970 e início dos anos 1980 mantinham forte articulação dos componentes da educação popular com os da teologia da libertação, e era marcante a centralidade das Comunidades Eclesiais de Base nos processos desenvolvidos no Brasil. Jurgen aponta para o fato de que, nos períodos iniciais das ações de Pão para o Mundo no Brasil, o foco de muitos projetos era a educação formal, a partir dos currículos escolares oficiais. Contudo, essa perspectiva foi sendo modificada, dada a natureza do estado brasileiro, e a dimensão da educação popular e de adultos passou a ser importante no apoio aos projetos.

0 mesmo foi afirmado por Alfred Rupert com relação aos apoios da Misereor: segundo ele, a metodologia de Paulo Freire era forte referência nos projetos brasileiros. Destacou também que tal método foi fundamental no trabalho de formação política das comunidades nos momentos da ditadura.

Para Manfred, os anos 1980 foram o período de maior presença e importância da educação popular nos apoios dados pela Cooperação Internacional. Na década seguinte, começaram a surgir questionamentos sobre a utilidade da educação popular, em função de seus aspectos por vezes "abstratos", no que diz respeito aos resultados. Para ele, esse pode ser o motivo pelo qual o número de organizações parceiras que trabalhavam com educação popular diminuiu com o passar dos anos.

Úrsula destaca a importância de Paulo Freire tanto nas agências quanto na sociedade alemã; contudo, isso não significava que houvesse condição ou pressão para que os projetos apoiados pela EZE/EED tivessem conteúdos relacionados à educação popular.

John afirma que era bastante próximo das teorias de Paulo Freire sobre alfabetização de adultos, ressaltando que o tema da conscientização foi um elemento muito importante para as mudanças nas posições assistencialistas que caracterizavam a cooperação holandesa nos anos 1970. As várias visitas de Paulo Freire à Holanda e, em especial, à Novib contribuíram para a mudança acima citada, já que era uma pessoa bastante respeitada e admirada. Na avaliação de Úrsula, as abordagens da educação popular variavam conforme as organizações brasileiras; já, do ponto de vista da sociedade holandesa, a educação popular era reconhecida como um caminho para a democratização, ou seja, um instrumento de liberação, e não um fim em si mesma.

A experiência das pessoas que atuaram na cooperação franco-belga apresenta elementos semelhantes. O CCFD considerava a dimensão da educação popular como fundamental nos projetos apoiados, mas, segundo Jackie, não era precondição para 
o apoio. Ela conta que na França havia experiências muito interessantes e próximas da educação popular, nascidas no período da resistência e que uniam intelectuais e operários, pois os primeiros reconheciam que não tinham a vivência concreta da realidade. Era um método muito semelhante ao ver, julgar e agir, utilizado pela Juventude Operária Católica. Jean Marie reconhece a importância da educação popular e de Paulo Freire nos anos 1980. A América Latina aparecia como uma referência de educação popular, e esta havia sido a força dos movimentos católicos nos anos 1940 e 1950 na França e que, no pós-1968, começava a perder a capacidade de alcançar a população adulta e os jovens. Assim, nessas duas décadas - 1970-1980 -, do ponto de vista da educação, as experiências da América Latina eram vistas mais no sentido de aprender a partir das experiências inovadoras que estavam sendo produzidas. Ele considera que algumas ideias, como o teatro do oprimido, influenciaram certo tipo de educação para o desenvolvimento; inclusive, algumas ONGs francesas utilizaram esses métodos para a conscientização e a educação. Acredita que o tema da educação popular resultou em processo de aprendizagem mútua entre organizações francesas e brasileiras.

\section{A influência de Paulo Freire}

Paulo Freire saiu do País em setembro de 1964, depois de pedir asilo na embaixada da Bolívia e para lá seguir, por sentir-se ameaçado pela ditadura militar. Da Bolívia seguiu para o Chile, onde permaneceu de novembro de 1964 a abril de 1969, junto com outros companheiros exilados, trabalhando como assessor no Ministério de Educação daquele país e como consultor da Unesco. Em abril de 1969, mudou-se para os Estados Unidos, aceitando convite para dar aulas na Universidade de Harvard como professor convidado. Em fevereiro de 1970, seguiu para Genebra, para trabalhar no Conselho Mundial de Igrejas. Seu pensamento foi ganhando relevância internacional, como pudemos identificar nos depoimentos acima. Freire, a partir da Suíça, trabalhou em diversos países de vários continentes. Na África, em particular em Cabo Verde, Angola e, principalmente, Guiné-Bissau, auxiliou no trabalho de reconstrução educacional, em propostas que ajudaram no processo de descolonização das consciências da população negra e na busca das suas identidades históricas.

No Brasil, nos anos 1960 e 70, era o tempo da vigência de práticas educativas, no âmbito da sociedade civil, denominadas Educação Popular, em paralelo ao sistema formal de ensino gerido sob a influência dos governos militares. Paulo Freire não es- 
tava mais aqui, mas seu pensamento foi se enraizando nas concepções e nas práticas de educadores populares e ativistas. Buscava-se reconstruir o tecido social a partir da base da sociedade, com metodologias participativas, horizontalizadas, que tinham na sua intencionalidade a politização, a tomada de consciência dos problemas sociais e a organização da população para tentar superá-los. Os principais agentes dessas experiências educativas foram as CEBs e as ONGs, muitas delas nascidas do próprio trabalho das Igrejas. As ações dessas organizações só foram possíveis graças à solidariedade internacional traduzida nos mecanismos de cooperação europeia que, por intermédio das organizações da sociedade civil do Norte, carrearam apoio político e financeiro para que o trabalho político da educação popular pudesse ser desenvolvido e o pensamento de Freire, vivenciado.

A influência de Paulo Freire não só ocupou centralidade nas experiências dessas organizações, como ganhou reconhecimento que permanece até os dias de hoje, em muitos dos trabalhos com organizações populares, entidades da sociedade civil, movimentos sociais e sindicais.

Importante destacar como o pensamento do educador ganhou centralidade nas agências europeias de cooperação naquele momento histórico, ao ajudar a fundamentar pedagogicamente a transição dessa cooperação, de uma perspectiva inicialmente assistencial, para a concepção de promoção para o desenvolvimento baseado na linguagem dos direitos humanos e no protagonismo da sociedade civil. No período europeu do seu exílio, Paulo Freire não só influenciou as agências como participou dos processos de descolonização na África, o que possibilitou conteúdos e fundamentos novos, que deram e dão sentido a muitas práticas educativas da sua pedagogia crítica.

Este texto abre uma janela para o invisível, para o pouco estudado: a cooperação internacional europeia, a influência de Paulo Freire nela e o papel das ONGs. Talvez pelas marcas que a ditadura, no Brasil, tenha deixado, muitas das práticas políticas daquele período não foram conhecidas. A educação popular foi um dos focos da atuação política dos educadores e educadoras que buscaram reconstituir a democracia brasileira a partir da base da sociedade. Paulo Freire foi a maior inspiração para essas práticas. As CEBs e as ONGs foram as institucionalidades que viabilizaram muitas dessas ações educativas. A cooperação internacional forneceu o suporte para que essas últimas pudessem existir. 


\section{Referências bibliográficas}

PEDROTTI, Paula Maciel. Acooperação internacionale terceira onda da democratização: o hibridismo da Fundação Konrad Adenauer e a experiência brasileira. Dissertação (Mestrado) - Escola de Administração de Empresa de São Paulo, Fundação Getúlio Vargas, São Paulo, 2005.

ROQUE, Átila. Cooperação internacional e democracia: agências não governamentais europeias e ONGs no Brasil. Dissertação (Mestrado) - Instituto Universitário de Pesquisas do Rio de Janeiro (luperj), Universidade Cândido Mendes, Rio de Janeiro, 2001.

RYFMAN, Philippe. Les ONG. Paris: Éditions La Découverte, 2009.

Submetido à avaliação em 16 de dezembro de 2013.

Aprovado para publicação em 16 de setembro de 2014 . 